\title{
Study of Mechanical Behavious and Characterization of a Steel Joints in MIG Welding under Varying Fluxes
}

\author{
Sunday Adeniran Afolalu*1, Samuel Olusegun D. ${ }^{2}$, Ikumapayi M.O, Oladipupo Segun ${ }^{1}$, Emetere Moses $^{3}$, \\ ${ }^{1}$ Department of Mechanical Engineering, Covenant University, Ota, Nigeria. \\ ${ }^{2}$ Department of Mechanical Engineering, Federal University of Petroleum Resources, Effirun Delta State. Nigeria. \\ ${ }^{3}$ Department of Physics, Covenant University, Ota, Nigeria.
}

\begin{abstract}
A lot of research work has been carried out varying welding parameters and studying its effects but rare work has been done on application of fluxes in MIG welding. Two different FeO based fluxes; Nano-flux and easy- flo flux powder were applied to the joints of $10 \mathrm{pcs}$ each of $50 \times 50 \mathrm{~mm}$ stainless and mild steel rods, galvanized and mild steel plates using MIG welding process. The samples used were welded under three categories; includes without flux (control), with nano-flux and easy-flow type-flux powder. The weld of the joints were subjected to mechanical test; hardness, tensile and morphological test; SEM and TEM examinations. The weld joints produced using the fluxes were found to have higher average values of hardness and tensile (stress and strain) of $222.73 \mathrm{BHN}, 0.03125$ and 199.97 BHN, 0.02785 respectively compare to samples without flux having lowest value of $131.36 \mathrm{BHN}, 0.01323$. The Microstructural analysis results with the use of SEM and TEM were found to have a better ordered grain structure and improved the structure, surface and pattern of the weld than those produced without flux.. The results obtained has revealed the impact of flux in MIG welding for joining steel gave better joint hardness and the structure of the weld.
\end{abstract}

Keywords: Nano, Nanoparticles; Nano-Flux; Powder; Welding; MIG welding; Morphology; Characterization; Iron Oxide.

\section{INTRODUCTION}

The history of metal joining stretches back several thousand years to the iron and bronze ages in Europe and the Middle East. Iron welding was credited by Herodotus the Ancient Greek historian as having been invented in the 0500s in the city of Chios by a man called Glaucus, and iron welding was used greatly in the Middle East and Asia to construct various objects and buildings like the Iron pillar of Delphi built in 310 A.D in Delhi, India with an estimated weight of about 5.4 tons.[1] The middle Ages saw great advancements take place in the various welding processes especially forge welding, in which metal was heated then pounded together repeatedly until bonding occurs and the metal welds together[2]. This process formed the backbone of work that went on during the renaissance with craftsmen being very skilled in the process [3].
In the $19^{\text {th }}$ century, improvements to the process of welding started in earnest with discovery of the "short pulse" electric arc and the continuous electric arc by Sir Humphry Davy and Vasily Petrov, this resulted in the invention of the first electric arc welding process using carbon electrodes in 1880 by Nikolai Benardos and Stanislaw Olszewski [4]. Further improvements that occurred were invention of metal electrodes in 1888 by Slavyanov and Coffin, the development in Britain of a metal electrode covered with suitable coating by A. P. Strohmenger in 1900 which gave a stable arc as an addition [5]. In 1905, the use of a three-phase electric arc was suggested by Vladimir Mitkevich. Cheles Johann Holslag developed alternating current welding in 1919 but for another decade the process did not gain overall usage [6].

MIG welding process is an efficient welding process used in high quality welding to produce clean and strong welds, but its use has been mainly restricted to the welding of thin layers of materials in the industry due to the small weld penetration gotten when it is used. In order to solve this problem [7-9]. Activated-flux MIG welding was introduced as a method of increasing the weld penetration of the MIG welding process and make it possible to use it for thicker materials. The fluxes used for this process are commonly made from inorganic chemical compounds which can be very expensive and quite harmful to the environment [10]. This work aims to use commonly found organic waste materials to synthesize these fluxes or to be used as additives for the fluxes [11-12].

Nanoparticle flux powder can be made through a variety of processes, from bottom up processes like green synthesis, sol gel method and biochemical synthesis to Top down processes like grinding, chemical etching etc. [13]. The Nanoparticle flux powders created were applied in the Activated-flux Metal Inert Gas welding of Metal rods (Stainless steel, Mild steel) and metal plates (Mild steel and Galvanised steel) [14]. Their mechanical properties were checked to analyse the effect that the powder had on the weld compared to ordinary Autogenous MIG welding of the metal rods and plates. Welding has various advantages, disadvantages and applications [15]. Welding is made easy in every position when using MIG. Due to the neatness of the weld, only very little work is done on the finishing. It weld metals that are usually never easy to weld. Arc and weld pool are easier to see when MIG welding is used. On the other side, there is a possibility of occurrence of error if 
International Journal of Engineering Research and Technology. ISSN 0974-3154, Volume 13, Number 6 (2020), pp. 1300-1306

(C) International Research Publication House. https://dx.doi.org/10.37624/IJERT/13.6.2020.1300-1306

the operator is not very skilled [16]. The welding location has to be covered for jobs done outdoors. It requires high capital and maintenance. Its application varies wildly from metals that it is most compatible with to the industries in which it can be applied. Metals like steel, aluminum and copper is joined with MIG and industries like ship building, automobile and aircrafts apply it [17]. A lot of research work has been carried out varying welding parameters and studying its effects but rare work has been done on application of fluxes in MIG welding, so this work will be focusing to check the impact of flux powder when applying to a joint of steel using MIG welding process for the joining.

\subsection{METHODOLOGY}

The procedure used while undertaking this experiment are explained in this section, It gives a brief overview on the materials used for the welding process, the application and also analysis that was carried out during the experiment.

\subsection{Preparation of metals}

Galvanised and mild steel plates, mild and stainless-steel rods were cut with a disc cutter into 10 by $50 \mathrm{~mm} \times 50 \mathrm{~mm}$ respectively. The rods were then turned on the lathe machine into $5 \mathrm{~mm}$ diameter dumb bell-shaped rods for the tensile tests.

\subsection{Application of flux powder}

Two different FeO based fluxes; Nano-flux and easy- flow flux powder were applied to the joints of 10 pcs each of $50 \times 50$ mm stainless and mild steel rods, galvanized and mild steel plates using MIG welding process. The samples used were welded under three categories; iincludes without flux (control), with nano-flux and easy-flow type-flux powder. it was applied in the MIG welding process using the setups shown in figure 1 below process involved acquisition and preparation of the metal samples, application of flux powder onto edges to be joined and the actual welding process.

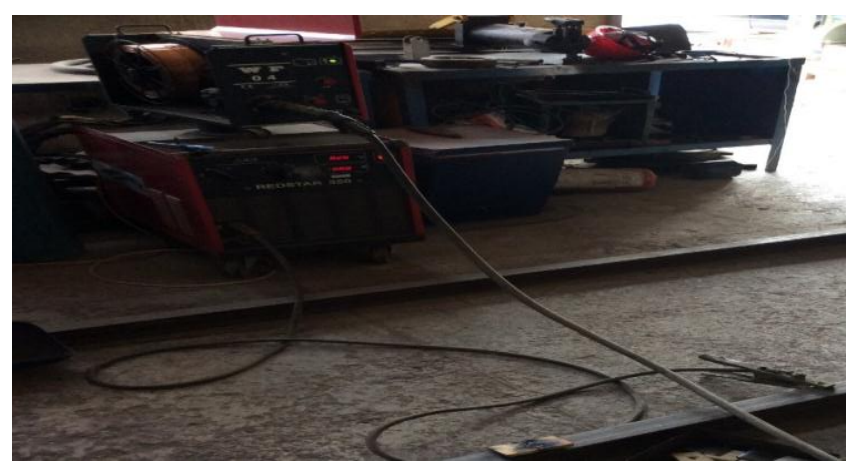

Figure 1. The MIG welding setup

\subsection{Welding}

The welding of both plate and rod using the developed flux powder was carried out in a MIG welding and the joints produced include GS-GS plate, MS-MS plate, SS-SS plate, MS-MS rod and SS-SS rod. 3 samples of each were produced, one as control without any flux powder, one was prepared using control Flux powder and the last one was prepared using the
Nano-flux powder developed from this project. The MIG welding was carried out using a voltage of $20 \mathrm{~V}$, wire feed rate of $2 \mathrm{~m} / \mathrm{hr}$, arc gap of $5 \mathrm{~mm}$.

Table 1: MIG Welding Parameters for the Experiment

\begin{tabular}{lllll}
\hline & $\begin{array}{l}\text { Weldin } \\
\text { g } \\
\text { Voltag } \\
\text { e (V) }\end{array}$ & $\begin{array}{l}\text { Wire } \\
\text { Feed } \\
\text { rate } \\
(\mathrm{m} / \mathrm{hr})\end{array}$ & $\begin{array}{l}\text { Fas } \\
\text { Rate } \\
(\mathrm{L} / \mathrm{min}\end{array}$ & $\begin{array}{l}\text { Arc } \\
\text { Gap } \\
(\mathrm{mm})\end{array}$ \\
\hline $\begin{array}{l}\text { MIG welding } \\
\begin{array}{l}\text { (Plates) } \\
\text { MIG }\end{array}\end{array}$ & 20.0 & 2.0 & 8.0 & 5.0 \\
$\begin{array}{l}\text { (Rods) } \\
\text { (Rolding }\end{array}$ & 20.0 & 2.0 & 8.0 & 5.0 \\
\hline
\end{tabular}

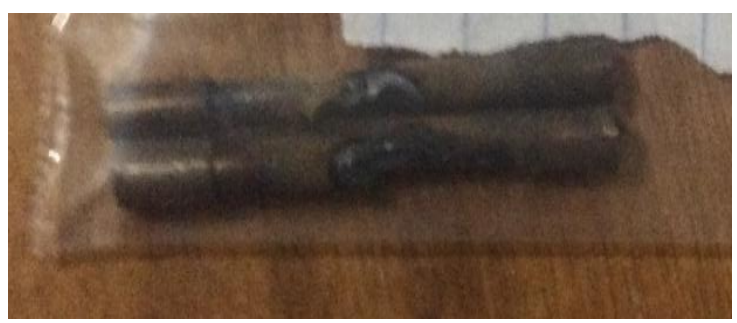

Figure 2: Mild steel rod

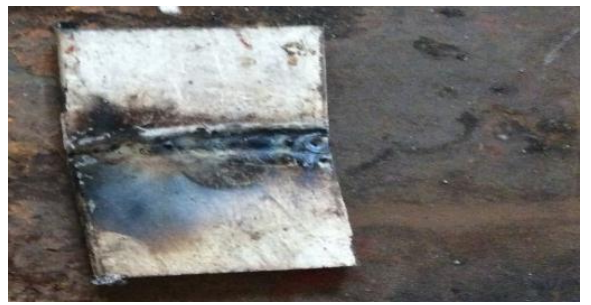

Figure 3: Galvanized steel plate

\subsection{Experimental Analysis}

The produced joints were then taken for SEM, hardness and tensile test. The result gotten from the tests were used to validate the viability of coconut shell as a source for Flux powder for TIG and MIG welding and its effect on the weld produced.

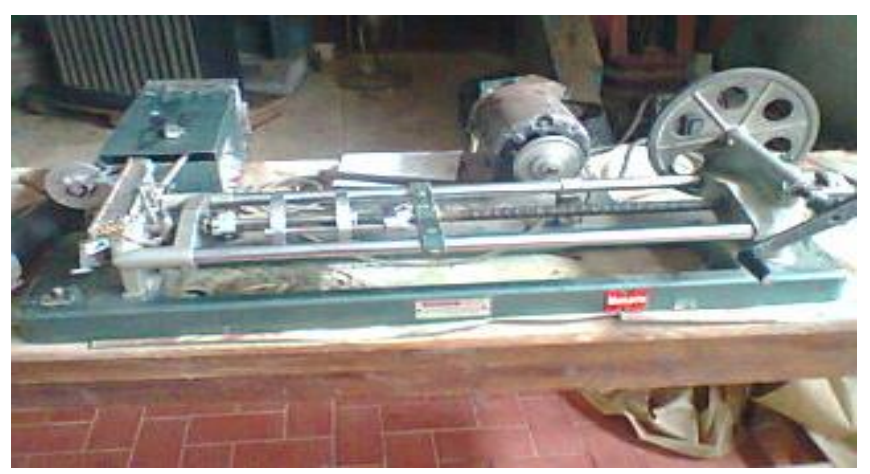

Figure 4: Monsanto Hardness Testing machine 


\section{0}

\section{RESULTS AND DISCUSSION}

Using different equipment to analyse the results of the developed flux on MIG welding it was observed that it had better properties and is more suitable for industrial use than the control and the MIG welding without flux.

\subsection{Scanning Electron Microscopy Test}

The samples were tested using the JSM-7600F Schottky Field Emission Scanning Electron Microscope. SEM images produced is shown below, with the image analysis done using the Digimizer ${ }^{\mathrm{TM}}$ software. The SEM micrographs was analyzed using the Digimizer ${ }^{\mathrm{TM}}$ image analysis software.

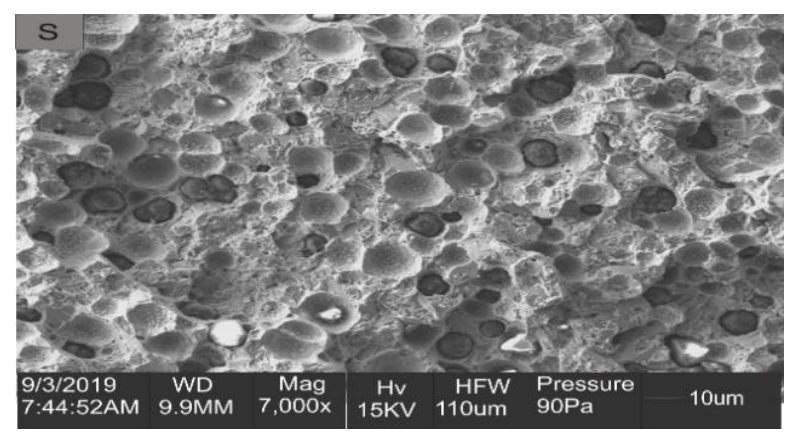

Figure 5: SEM micrographs of flux

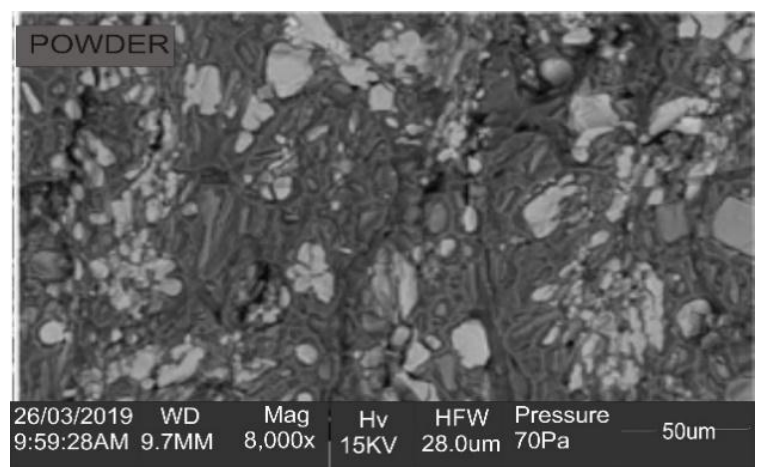

Figure 6: SEM micrographs of Control flux

\subsection{Electro-Dispersive X-ray Spectroscopy (EDS)}

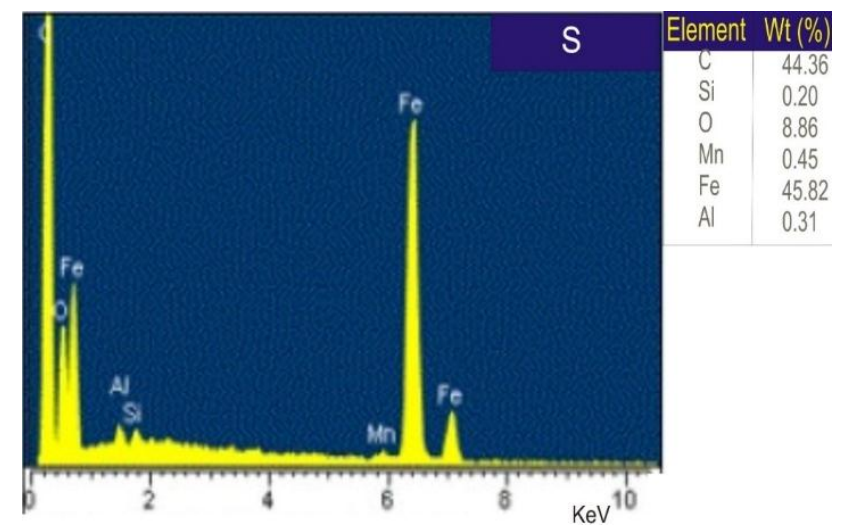

Figure 7: EDS micrograph of Nano- flux powder

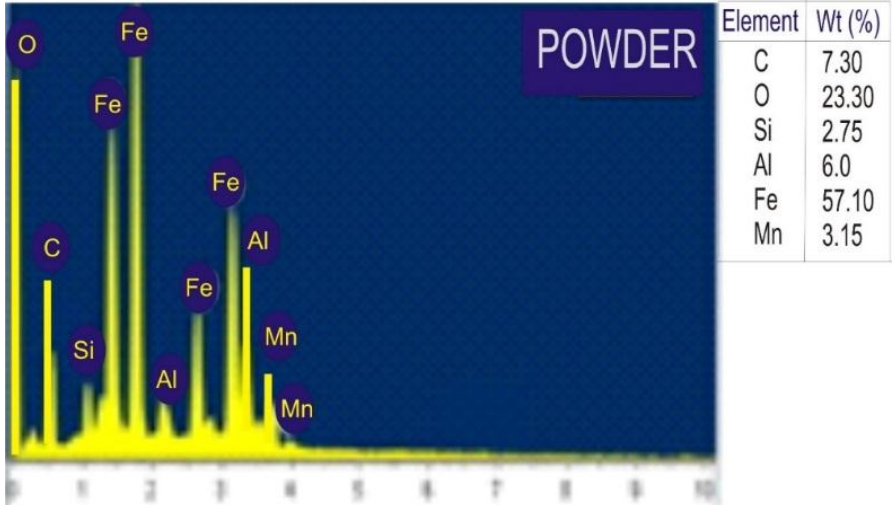

Figure 8: EDS micrographs of easy flow flux

It can be seen from the EDS graph in figure 7 and 8 that the combination of $\mathrm{Fe}, \mathrm{C}$ and $\mathrm{O}$ in the developed flux with respective concentration of $45.82,44.36$ and $8.86 \%$ delivered a better result because of the increase in carbon present, which produced better bonding as compared with the control flux which was made of $\mathrm{Fe}, \mathrm{O}, \mathrm{C}$ and $\mathrm{Al}$ with concentrations of 57.1, 23.3, 7.3 and $6 \%$.

\subsection{Hardness Test}

Brinel hardness test was carried out on the welds using the Monsanto testing machine and the results shown in table 2, the three regions of the created weld i.e. Base Metal, welded joint and the heat affected zone were tested.

Table 2: Brinell hardness Test results for MIG welds of Mild steel plates

\begin{tabular}{cccc}
\hline SAMPLE & $\begin{array}{c}\text { Nano } \\
\text { Flux }\end{array}$ & $\begin{array}{c}\text { Control without } \\
\text { Flux }\end{array}$ & $\begin{array}{c}\text { Easy Flow } \\
\text { Flux }\end{array}$ \\
\hline Base metal & 258.05 & 200.48 & 267.9 \\
Welded joint & 222.73 & 181.36 & 199.99 \\
$\begin{array}{c}\text { Heat affected } \\
\text { zone }\end{array}$ & 94.45 & 81.67 & 118.56 \\
\hline
\end{tabular}

Table 3: Brinell hardness Test results for MIG weld of Galvanized steel plates

\begin{tabular}{cccc}
\hline SAMPLE & $\begin{array}{c}\text { Nano } \\
\text { Flux }\end{array}$ & $\begin{array}{c}\text { Control without } \\
\text { Flux }\end{array}$ & $\begin{array}{c}\text { Easy Flow } \\
\text { Flux }\end{array}$ \\
\hline Base metal & 131.58 & 83.75 & 125.76 \\
Welded joint & 100.93 & 86.89 & 112.75 \\
$\begin{array}{c}\text { Heat affected } \\
\text { zone }\end{array}$ & 149.61 & 116.74 & 120.5 \\
\hline
\end{tabular}

From Table 2 and 3 it can be seen that in the base metal region, the control welds created without flux for Mild steel using MIG were lesser than those created using the nano- flux and easy flow flux, however for the galvanized steel joints the MIG weld created with the nano flux was harder than all the other welds created, and in the welded joint region, it was found that the 
welds produced using the nano flux using the MIG welding processes had a much higher Brinell harness value than those produced using the control flux powder and those produced without using any powder. In the heat affected zone it was found that the hardness of the zone was highest in the welds created with the control flux, and lowest in the welds created using the developed flux. This indicates that the nano flux and easy flow flux did a good job of increasing the hardness of the weld joint and increasing the ductility of the weld joint as seen in the tensile test results.

\subsection{Tensile Test}

Table 4: Tensile Test results for MIG welds of Mild steel rods

\begin{tabular}{lccc}
\hline \multicolumn{1}{c}{ Parameters } & Nano flux powder & Easy flow flux powder & Control without flux \\
\hline $\begin{array}{l}\text { Load at Maximum } \\
\text { Tensile Stress (N) }\end{array}$ & 3287.1682 & 1428.419 & 1225.539 \\
$\begin{array}{l}\text { Maximum Tensile Stress } \\
(\mathrm{MPa})\end{array}$ & 689.8444 & 525.95 & 372.5847 \\
$\begin{array}{l}\text { Maximum Tensile Strain } \\
(\mathrm{mm} / \mathrm{mm})\end{array}$ & 0.03125 & 0.03785 & 0.02323 \\
\hline
\end{tabular}

Table 5: Tensile Test results for MIG welds for stainless steel rods

\begin{tabular}{lccc}
\hline Parameters & $\begin{array}{c}\text { Nano flux } \\
\text { powder }\end{array}$ & Easy flow flux powder & Without flux Control \\
\hline Load at Maximum Tensile Stress $(\mathrm{N})$ & 3860.0303 & 3028.341 & 2859.563 \\
Maximum Tensile Stress (MPa) & 340.3562 & 252.612 & 152.1405 \\
Maximum Tensile Strain $(\mathrm{mm} / \mathrm{mm})$ & 0.03452 & 0.04456 & 0.02262 \\
\hline
\end{tabular}

From table 4 and 5 the results for the tensile test of MIG welds of mild steel and stainless steel rods gotten showed that the application of the locally developed flux powder led to the achievement of a much higher load at maximum tensile stress for the of 3287.1682 and $3860.0303 \mathrm{~N}$ and maximum tensile stresses of 289.8444 and $340.3562 \mathrm{MPa}$ in Mild and Stainless steel welds respectively in the weld produced when compared to the Control welds created with control flux which had load values of 1428.419 and $1028.341 \mathrm{~N}$, max stresses of 125.95 and 252.612 MPa and those created without the use of flux which had load values of 133.7416 and $1334.9073 \mathrm{~N}$, max stresses of 11.7926 and $117.7048 \mathrm{MPa}$. From these results its seen that for the Stainless-steel welds, those produced with the nano flux had highest values of Load at maximum stress, Maximum Tensile stress and Maximum tensile strain with those produced without flux having the second highest values and for the Mild steel welds, the welds produced with the Easy flow flux had the highest values of Load at maximum stress, Maximum Tensile stress and Maximum tensile strain with those produced with the developed flux having the second highest values. These results showed that the Nano flux had the effect of improving the tensile properties of the weld produced. Showing that using of flux powder in the MIG welding process results in increased load bearing capacity, higher tensile stress and lowest tensile strain.

\subsubsection{Stress and Strain Graphs}
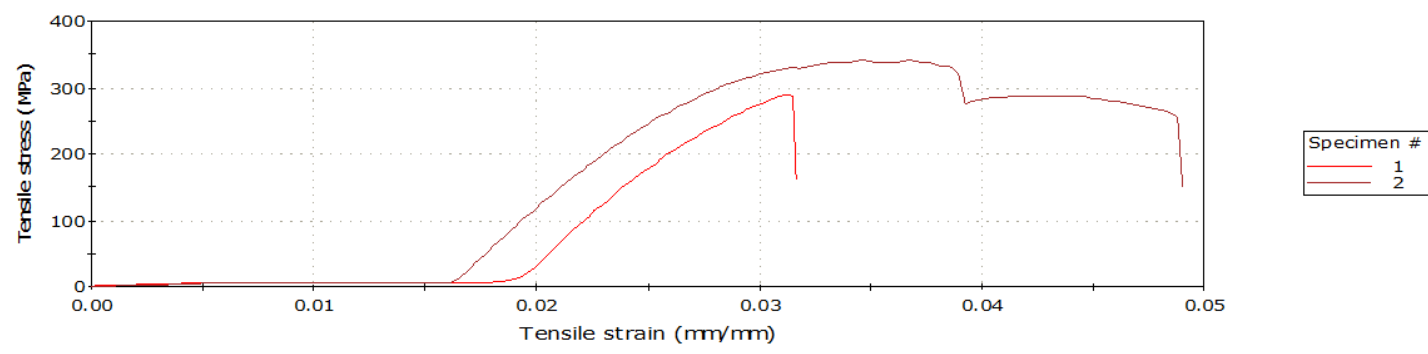

Figure 9: Stress-Strain curve of MIG weld produced with developed flux. 
International Journal of Engineering Research and Technology. ISSN 0974-3154, Volume 13, Number 6 (2020), pp. 1300-1306

(C) International Research Publication House. https://dx.doi.org/10.37624/IJERT/13.6.2020.1300-1306

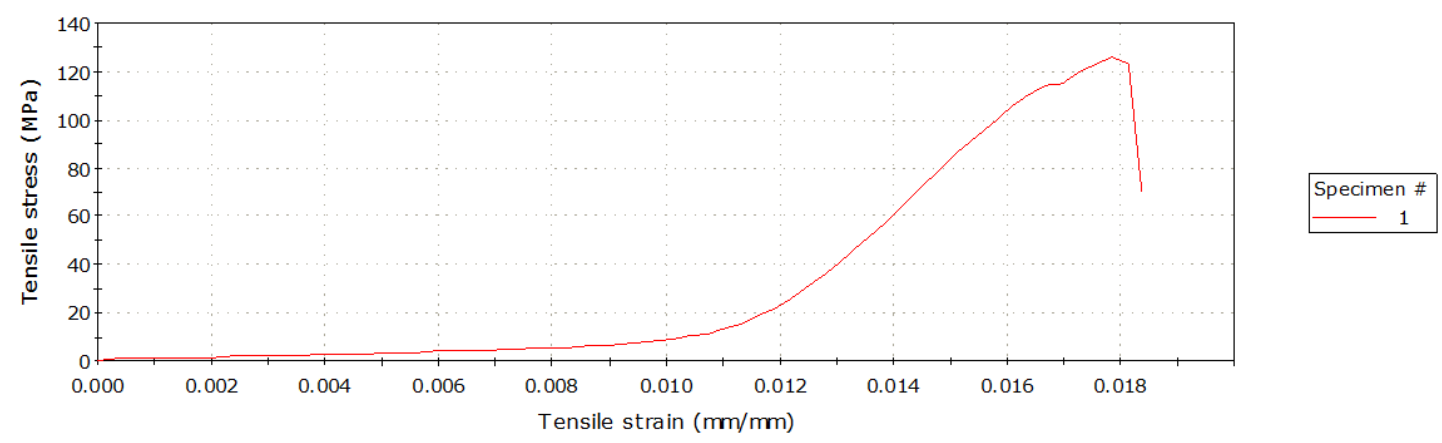

Figure 10: Stress-Strain curve of MIG weld produced with control flux.

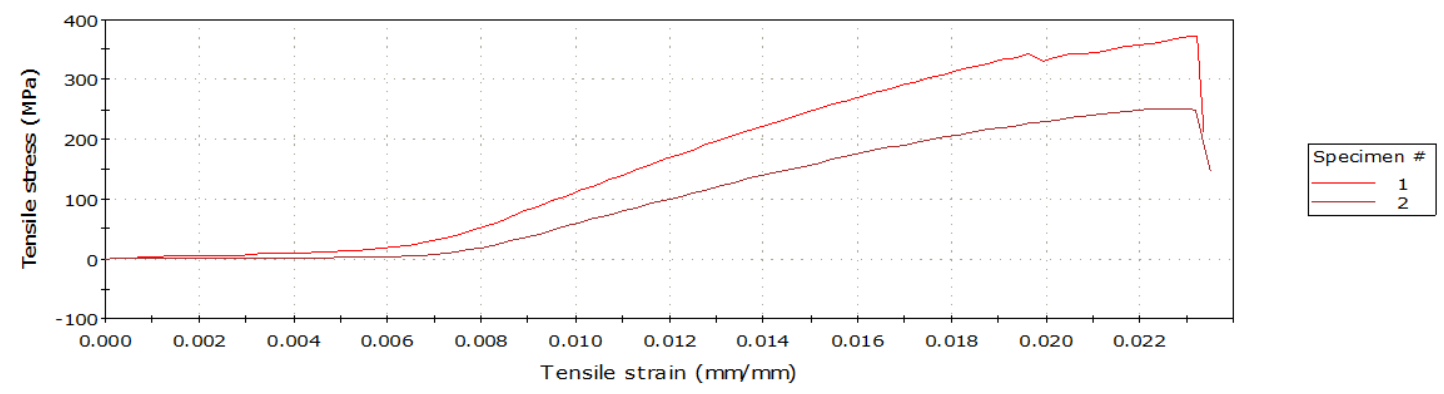

Figure 11: Stress-Strain curve of MIG weld produced without flux

Compared to the stress-strain curves of MIG weld created using developed flux in figure 9, those welds created using the control flux as shown in figure 9 were found to be weaker and have points at which sudden rupture occurs, though the points of rupture are not as steep as those witnessed in welds created without using flux as shown in figure 11, they were far steeper than those created using the developed flux powder. Compared to the welds created using Control flux powder, the welds created using the developed flux was found to be stronger, exhibiting higher Maximum tensile stress and Maximum load.

\subsection{SEM Test Results}

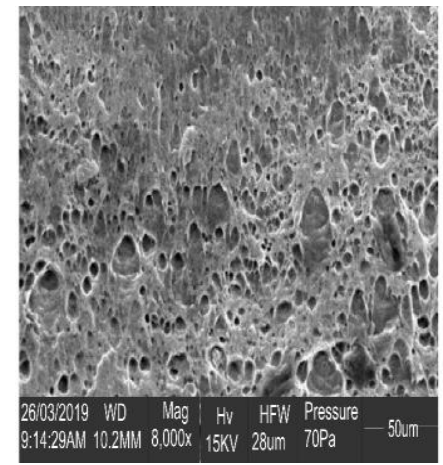

(a)

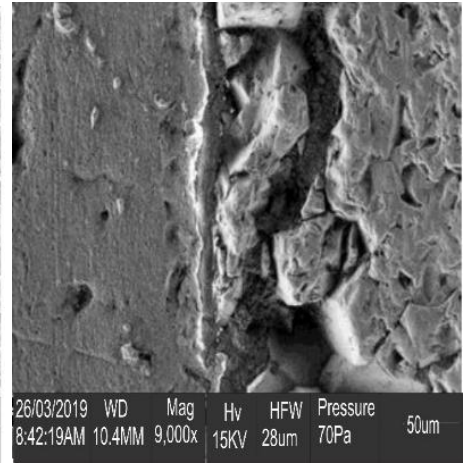

(b)

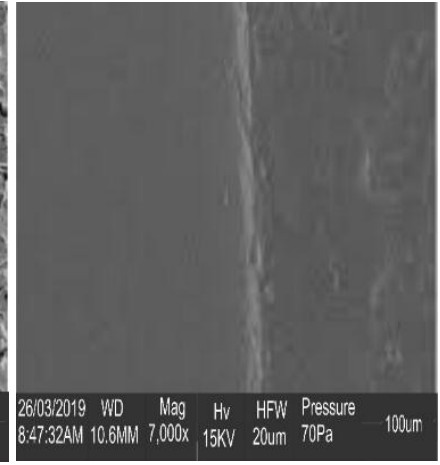

(c)

Figure 12: SEM micrographs of MIG weld of Mild steel samples produced (a) with Nano flux, (b) Easy flow flux and (c) without flux powder

The SEM micrograph of the welds created without the use of flux showed that the microstructure of the produced weld was similar to that of the base material with the metal structure being rough and rakish. There is presence of pearlite and martensite structure in the weld leading to the reduced structure of strength. The SEM micrograph of Mild steel welded using the nano flux and the MIG welding process showed a lot of variation with the existence of air gaps due to porosity in the weld produced as seen in figure 12, strengthening dislocations are also present in this microstructure but they are not as plenty as those in the weld created using flux. 


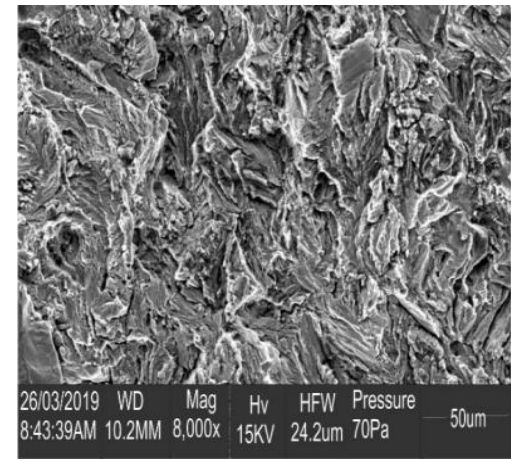

(a)

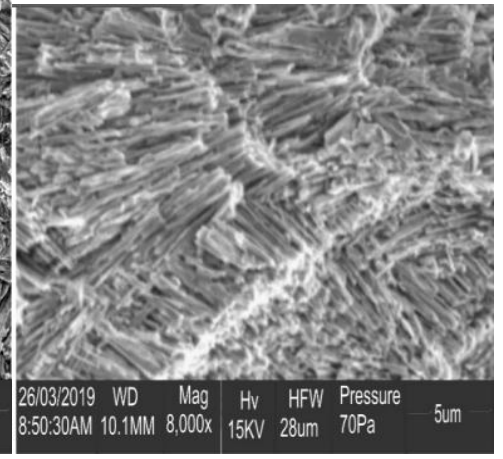

(b)

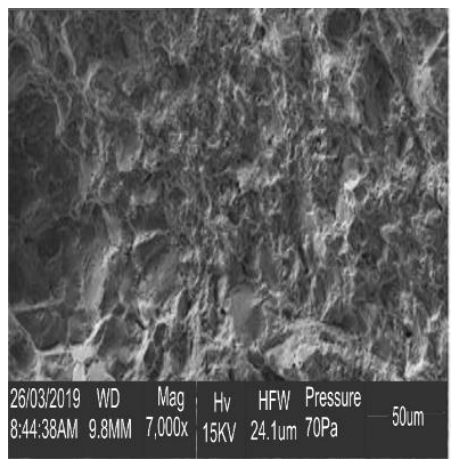

(c)

Figure 12: SEM micrographs of MIG weld of Galvanized steel samples produced (a) with

\section{Nano- flux, (b) Easy flow flux and (c) without flux powder}

The SEM micrograph of the welds created without the use of flux showed that the microstructure of the produced weld was similar to that of the base material with the metal structure being rough and rakish. There is presence of pearlite and martensite structure in the weld leading to the reduced structure of strength. The SEM micrograph of Mild steel welded using flux and the MIG welding process showed a lot of variation with the existence of air gaps due to porosity in the weld produced as seen in figure 12, strengthening dislocations are also present in this microstructure but they are not as plenty as those in the weld created using the flux.

Microstructure of the MIG weld of the galvanized steel was found to be very disordered being a combo of martensite and pearlite lacking the order present in the weld made with flux. The weld done without the use of flux possessed contours with shapes like a valley. The weld done with control flux however is smooth and it has some lightly colored deposits different from the overall composition of the weld which may be attributed to the use of the flux powder. It also has tiny dents that look like pore spaces. The weld done with the control flux exhibits strict lines and a surface filled with some dents.

\subsection{CONCLUSION}

The nano-flux powder contained $45.82 \% \mathrm{Fe}, 44.36 \% \mathrm{C}$ and $8.86 \% \mathrm{O}$ and the easy -flow flux powder was found to be made up of $57.1 \% \mathrm{Fe}, 23.3 \% \mathrm{O}$ and $7.3 \%$ which established that $\mathrm{FeO}$ based fluxes were used. On application of the nano flux in the MIG welding process on stainless and mild steel rods, galvanized and mild steel plates, the flux led to an increase in the hardness and tensile stress and strain of the weld joint compared to the welds produced without any welding flux. The weld produced is smooth and orderly crystalline, also has some lightly colored deposits with the overall composition of the weld which may be attributed to the high hardness and tensile value of the welds.

\section{ACKNOWLEDGEMENT}

The author acknowledged Covenant University for the financial support offered for the publication of this research.

\section{REFERENCES}

[1] Bello, S. A., Agunsoye, J. O., and Hassan, S. B (2015). Synthesis of coconut shell nanoparticles via a top down approach: Assessment of milling duration on the particle sizes and morphologies of coconut shell nanoparticles. Materials Letters, 159, 514-519.

[2] Bodkhe, S. C., and Dolas, D. R (2018). Optimization of Activated Tungsten Inert Gas Welding of 304L Austenitic Stainless Steel. Procedia Manufacturing, 20, 277-282.

[3] Cary, H. B., Helzer, S. C., (2005). Modern Welding Technology. Upper Saddle River, New Jersey: Pearson Education. ISBN 0-13-113029-3.

[4] Jeyaprakash, N., Haile, A., and Arunprasath, M (2015). The Parameters and Equipment Used in TIG Welding : A Review. The International Journal of Engineering and Science, 4(2), 11-20.

[5] Afolalu, S. A., Ongbali, S. O., Abioye, A. A., Oladipupo, S., Ajayi, O. O., \& Salawu, E. Y. (2019). Modelling and Simulation of Mechanical Wear of Carburized Cutting Tool. Procedia Manufacturing, 35, 1067-1072

[6] Anders, A (2003). Tracking down the origin of arc plasma science-II. Early continuous discharges. IEE transactions on plasma science, 31(5), 1060-1069.

[7] Patel, A. B., and Patel, P. S. P. (2014). The effect of activating fluxes in TIG welding by using Anova for SS 321. International Journal of Engineering Research and Applications, 4(5), 41-48.

[8] Singh, A. K., Dey, V., and Rai, R. N. (2017). Techniques to improve weld penetration in TIG welding (A review). Materials Today: Proceedings, 4(2), 1252-1259.

[9] Abouelmagd, S. A., Meng, F., Kim, B. K., Hyun, H., and Yeo, Y (2016). Tannic acid-mediated surface functionalization of polymeric nanoparticles. ACS biomaterials science and engineering, 2(12), 22942303.

[10] Afolalu, S. A., Efekodha, G. E., Ongbali, S. O., Abioye, A. A., Salawu, E. Y., Ajayi, O. O., \& Oluwabunmi, A. P. (2019). Experimental Analysis of the Effect of TriNano Additives on Wear Rate of Mild Steel during Machining. Procedia Manufacturing, 35, 395-400. 
International Journal of Engineering Research and Technology. ISSN 0974-3154, Volume 13, Number 6 (2020), pp. 1300-1306

(C) International Research Publication House. https://dx.doi.org/10.37624/IJERT/13.6.2020.1300-1306

[11] Tseng, K. (2013). Development and application of oxide-based fl ux powder for tungsten inert gas welding of austenitic stainless steels. Powder Technology, 233, 72-79.

[12] Anders, A (2003). Tracking down the origin of arc plasma science-II. Early continuous discharges. IEE transactions on plasma science, 31(5), 1060-1069.

[13] Vidyarthy, R. S., and Dwivedi, D. K. (2016). Activating flux tungsten inert gas welding for enhanced weld penetration. Journal of Manufacturing Processes, 22, 211-228.

[14] Udo, M. O., Esezobor, D. E., Apeh, F. I., \& Afolalu, A. S. (2018). Factors Affecting Ballability of Mixture Iron Ore Concentrates and Iron Oxide Bearing Wastes in Metallurgical Processing. Journal of Ecological Engineering Vol, 19, 3

[15] Mfon Udo, David Esezobor, Adeniran Afolalu, Harrison Onovo, Samson Ongbali, Imhade Okokpuji. (2018). Investigation of Balling Characteristics of Mixture of Iron Oxide Bearing Wastes and Iron Ore Concentrates. In IOP Conference Series Materials Science and Engineering (Vol. 413, No. 2, p. 012042). IOP Publishing.

[16] Anders, A (2003). Tracking down the origin of arc plasma science-II. Early continuous discharges. IEE transactions on plasma science, 31(5), 1060-1069.

[17] Cary, H. B., Helzer, S. C., (2005). Modern Welding Technology. Upper Saddle River, New Jersey: Pearson Education. ISBN 0-13-113029-3. 